\title{
AS FASES PORTADORAS DE NÍQUEL DO MINÉRIO LATERÍTICO DE NÍQUEL DO VERMELHO, SERRA DOS CARAJÁS (PA)
}

\author{
MARIA LUIZA MELCHERT DE CARVALHO E SILVA* \& SÔNIA MARIA BARROS DE OLIVEIRA****
}

\begin{abstract}
THE NI-BEARING PHASES OF THE LATERITIC ORE, VERMELHO DEPOSIT, SERRA DOS CARAJAS (PA). In the lateritic nickel deposit of Vermelho, Serra dos Carajás-PA, two types of ore can be recognized: the silicated ore at the bottom of the weathering profile, and the oxidized ore at the top. The mineralogical composition of the silicated ore (average grade $=1.8 \% \mathrm{wt} \mathrm{NiO}$ ) consists largely of serpentine, chlorite and spinels, with quartz and goethite in minor amounts. Serpentine and chlorite are the main nickel-bearing minerals, being $\mathrm{Ni}$ about equally distributed between the two phases $(2-3 \% \mathrm{wt} \mathrm{NiO})$. The oxidized ore (average grades $1.2 \% \mathrm{wt} \mathrm{NiO}$ ) is composed predominantly of goethite, containing also chlorite, spinels and quartz. In this case, nickel is highly concentrated in chlorite (average $12 \% \mathrm{wt} \mathrm{NiO}$ ), whereas in goethite it ranges between 0,9 and $1,7 \%$. As a result, the presence of chlorite, even in minor quantities, is important in raising the grade of the oxidized ore. Locally, higher grades of ore can also be due to the presence of nickeliferous smectites.
\end{abstract}

Keywords: Ni secondary minerals, Ni lateritic deposit, Vermelho deposit, Serra dos Carajás

RESUMO Na jazida laterítica de níquel do Vermelho, Serra dos Carajás-PA, podem ser reconhecidos dois tipos de minério: o silicatado, na base do perfil de alteração, e o oxidado, situado mais acima. No minério silicatado (teor médio de $1,8 \%$ em peso $\mathrm{NiO}$ ), os minerais presentes são serpentina, clorita, espinélios e, secundariamente, quartzo e goethita. Dentre esses, as serpentinas e as cloritas são os principais portadores de $\mathrm{Ni}$, que se distribui igualmente entre as duas fases, atingindo nelas teores da ordem de 2 a 3\% de NiO. O minério oxidado (teor médio de $1,2 \% \mathrm{NiO}$ ) é constituído principalmente por goethita, contendo ainda clorita, espinélios e quartzo. Nesse caso, o níquel encontra-se altamente concentrado na clorita, atingindo valores médios de $12 \% \mathrm{NiO}$, enquanto que na goethita apresenta valores entre 0,9 e $1,7 \% \mathrm{NiO}$. Dessa forma, mesmo presente em pequena quantidade, a clorita tem um papel importante na elevação do teor médio do minério oxidado. Localizadamente, a elevação dos teores do minério também pode ser devida ả presença de esmectitas níquel íferas.

Palavras-chaves: Minerais secundários de Ni, depósito laterítico de Ni, jazida do Vermelho, Serra dos Carajás

INTRODUÇÃO A jazida de níquel do Vermelho insere-se na Província Mineral de Carajás, estando situada na porção sul da serra, no estado do Pará (Fig. 1). É formada pela alteração laterítica de dois corpos de rochas máficoultramáficas, encaixados em rochas do Complexo Xingu. Estes corpos são formados por três unidades diferenciadas, numa disposição aproximadamente concêntrica, apresentando do centro para a borda dunitos e peridotitos intensamente serpentinizados, piroxenitos e gabros (Alves et al 1986). Na zona ultramáfica registra-se a presença de diques de natureza piroxenítica.

A Rio Doce Geologia e Mineração S/A - DOCEGEO - foi a empresa responsável pela avaliação das reservas do depósito. Os trabalhos de pesquisa foram efetuados através da abertura de poços em malha regular (espaçamento em geral de 50 por $50 \mathrm{~m}$ nas regiões de interesse) nos dois corpos de rochas ultramáficas denominados V1 e V2, complementados por furos de sondagem, análises químicas e ensaios metalúrgicos. Uma síntese dos resultados parciais obtidos na primeira fase de pesquisa foi apresentada por Alves et al. (1986). Bernardelli et al (1983) efetuaram estudos mineralógicos e químicos em amostras provenientes de poços de algumas topossequências do corpo VI. Outro poço, também do corpo VI, que apresentou teores médios anormalmente elevados de níquel na fase de pesquisa, foi estudado por Corrêa et al (1987) e complementa as informações disponíveis sobre o depósito. Os dados constantes na literatura sobre o Vermelho permitiram uma caracterização geral do

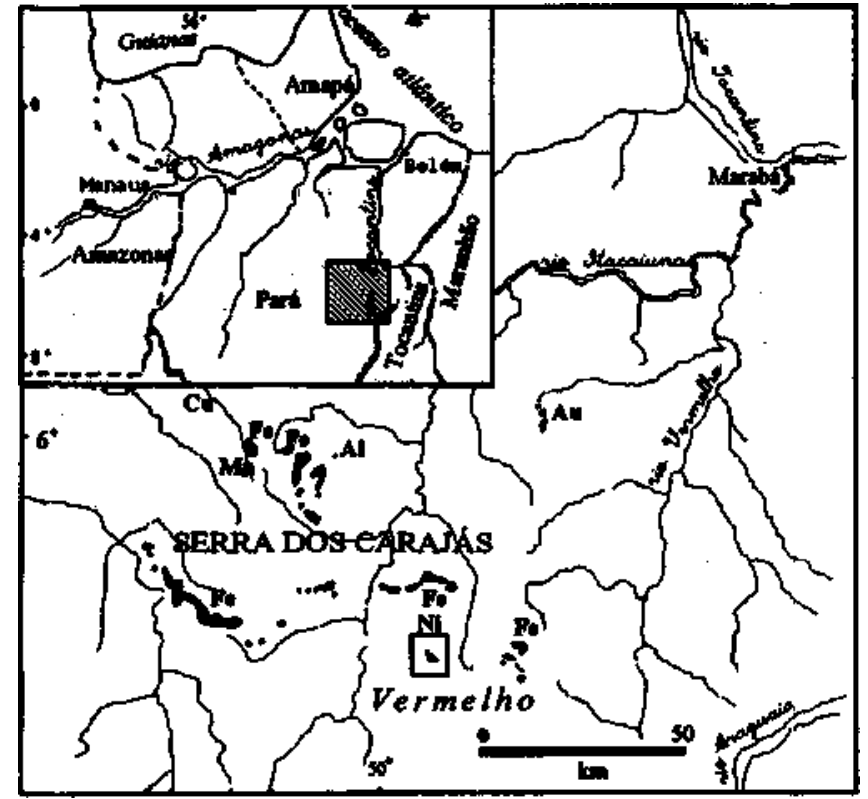

Figura 1 - Localização da jazida do Vermelho (modificado de Alves et al. 1986)

Figura 1 - Location map of the Vermelho ore deposit (modified from Alves etal. 1986)

* NUPEGEL - Núcleo de Pesquisa em Geoquímica e Geofísica da Litosfera, Universidade de São Paulo, Caixa Postal 9638, CEP 01065-970 FAX (011) 2763848, São Paulo, SP, Brasil

** Departamento de Geologia Geral, Instituto de Geociências, Universidade de São Paulo, Caixa Postal 11348, CEP 05422-970, FAX (011) 210-4958 São Paulo, SP, Brasil. 
depósito e o estabelecimento de um modelo genético, porém estudos mais detalhados não foram efetuados. Este trabalho apresenta os resultados de estudos que levaram a uma melhor identificação das fases minerais presentes no minério, à determinação das fases portadoras de níquel e a uma caracterização dos minerais niquelíferos mais importantes.

DESCRICÃO DO DEPÓSITO O depósito de níquel do Vermelho é constituído por perfis de alteração desenvolvidos essencialmente sobre os dunitos intensamente serpentinizados que estão situados na porção central dos dois corpos de rochas ultramáficas. Os perfis desenvolvidos sobre as demais rochas, incluindo os veios de piroxenito que cortam os dunitos totalmente serpentinizados, apresentam teores muito baixos de níquel, sendo considerados estéreis. Apesar das variações locais acarretadas pela heterogeneidade da rocha-mãe, pode-se estabelecer um perfil típico da jazida. Da base para o topo, este perfil incluiria os seguintes níveis: rocha pouco alterada, saprolito grosso, saprolito fino mais ou menos silicificado e laterita vermelha (presente nos topos e em encostas não abruptas). A Figura 2 mostra o perfil típico de encosta, a composição mineralógica dominante em cada nível e e os teores médios de $\mathrm{NiO}(\% \mathrm{em}$ peso), segundo Alves et al. (1986). São considerados minério apenas os níveis de saprolito grosso - minério silicatado - e saprolito fino - minério oxidado. Os teores de Ni são bastante variáveis em toda a jazida, tanto em profundidade, quanto entre os diferentes poços. Alves et al. (1986) citam teores máximos de $2 \% \mathrm{Ni}$ no minério oxidado e de $3-4 \% \mathrm{Ni}$ no silicatado. Localizadamente, no entanto, foram obtidos em alguns poços teores entre 5 e $9 \% \mathrm{Ni}$.

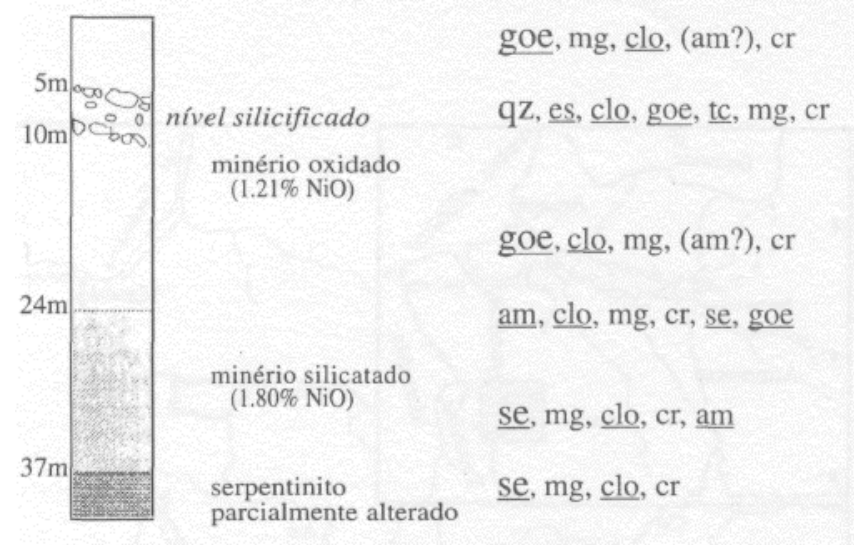

Figura 2 - Perfil de alteração típico de encosta no depósito do Vermelho (goe = goethita; $s e=$ serpentina; $m g=$ magnetita; clo = clorita; $\mathrm{cr}=$ cromita, $q z=$ quartzo; $a m=$ amorfos). Minerais sublinhados $=$ fases niqueliferas Figura 2- Typical weathering profile on the slopes, Vermelho deposit (goe = goethite; $\mathrm{se}=$ serpentine; $\mathrm{mg}=$ magnetite; $\mathrm{clo}=$ chlorite; $\mathrm{cr}=$ chromite; $\mathrm{qz}=$ quartz; $\mathrm{am}=$ amorphous phases). Outlined minerals $=$ nickeliferous phases

A rocha pouco alterada é constituída por serpentina, opacos e, eventualmente, restos de olivina e piroxênio, calcedônia e quartzo microcristalino, além de pequena quantidade goethita e produtos amorfos, de acordo com Bernardelli et al. (1983) e Alves et al. (1986).

No nível de saprolito grosso são descritas serpentinas e cloritas, além de esmectitas, opacos, quartzo e calcedônia (Alves et al. 1986, Bernardelli et al. 1983). Também produtos amorfos e goethita podem ser encontrados. Alves et al. (1986) acrescentam a presença de veios de garnierita, na base do perfil, e Corrêa et al. (1987) descrevem a presença de minério garnierítico no horizonte argiloso rico em níquel do poço estudado. O termo garnierita possui nestes dois trabalhos uma conotação genérica, significando silicates esverdeados de níquel.

Embora estudos mineralógicos mais detalhados não tenham sido efetuados, Bernardelli et al. (1983) sugerem que as fases portadoras do níquel no minério silicatado sejam as serpentinas e os produtos amorfos sílico-ferruginosos. Correa et al. (1987) consideram como principal fase portadora de níquel, no poço estudado, as esmectitas que, no entanto, constituiriam apenas fases acessórias no panorama geral da jazida, segundo Bernardelli et al. (1983) e Alves et al (1986). A natureza deste argilomineral é apenas sugerida pelos autores, montimorilonítica para Corrêa et al. (1987) e Alves et al. (1986), nontronítica para Bernardelli et al. (1983).

Com relação ao minério oxidado, sua constituição mais simples é consenso entre os diferentes autores, que registram a presença de goethita, clorita, quartzo, espinélios e, em menor proporção, caulinita. A goethita é a fase mineral apontada como portadora do níquel. A silica, presente sob a forma de quartzo e calcedônia, distribui-se em finos veios em vários níveis do perfil de alteração, mas se concentra em duas zonas distintas (entre 5-10m e entre 18-22m) do minério oxidado, constituindo um verdadeiro silcrete. Blocos silicificados encontrados imersos no saprolito fino podem apresentar restos de rocha fresca a parcialmente alterada no centro.

Dois estágios são propostos por Bernardelli et al. (1983) para a gênese do depósito. O primeiro, sob condições climáticas mais secas, levou a uma silicificação generalizada, principalmente ao longo das fraturas, na base do perfil, isolando bolsões de rocha fresca. Posteriormente, uma mudança climática favoreceu a erosão e um novo ciclo de laterização que atingiu esses bolsões e levou ao desenvolvimento de um perfil laterítico abaixo do nível silicificado. Essa história evolutiva foi apresentada para quase todos os depósitos lateríticos de níquel brasileiros (Oliveira et al. 1992), assim como para alguns depósitos australianos (Nickel \& Thornber 1977).

\section{CARACTERIZAÇÃO QUÍMICA DO DEPÓSITO}

Para esse trabalho foram retomadas amostras de rocha fresca, parcialmente alterada, minério silicatado e minério oxidado provenientes de V1, estudadas por Bernardelli et al. (1983), complementadas por amostras de dois poços de V2. A laterita vermelha e os perfis desenvolvidos sobre os piroxenitos que apresentam baixos teores de níquel não foram estudados. Embora refentes a apenas alguns poços abertos no depósito, os dados químicos médios dos materiais estudados são coerentes com os teores médios e as faixas de variação apresentados por Alves et al. (1986) para o depósito como um todo. Na tabela 1 são apresentados os dados de análises químicas de amostra total para os diferentes níveis do perfil de alteração em V1 e V2.

Como é habitual nesse tipo de depósito, os teores de $\mathrm{MgO}$ e $\mathrm{SiO}_{2}$ diminuem da base para o topo do perfil de alteração, enquanto os de $\mathrm{Fe}_{2} \mathrm{O}_{3}$ aumentam. A queda relativamente brusca no teor de magnésio, acompanhada pelo aumento do ferro, marca a passagem do minério silicatado para o oxidado. O teor médio de $\mathrm{NiO}$ é mais elevado no minério silicatado do que no oxidado. $\mathrm{Cr}$, $\mathrm{Co}$ e $\mathrm{Al}$, ao contrário, estão mais concentrados nos níveis oxidados. Algumas diferenças entre os dois corpos podem ser observadas. O minério silicatado em V2 é mais pobre em $\mathrm{SiO}_{2}$ e $\mathrm{MgO}$ do que o de $\mathrm{VI}$, ao contrário do oxidado, que apresenta teores de $\mathrm{SiO}_{2}$ e $\mathrm{MgO}$ da mesma ordem de grandeza em V2 e VI. Além disso, os teores de níquel são mais elevados nos dois tipos de minério de V2. Destaca-se, ainda, neste corpo a presença de um nível silicificado, na 
Tabela 1 - Composição química média (\% em peso) dos diferentes níveis do perfil de alteração ( $n=$ número de amostras; $P F=$ perda ao fogo)

Table 1 - Mean chemical composition ( $w$ t \%) of the different levels of the weathering profile $(n=$ number of samples; $P F=$ loss of ignition)

\begin{tabular}{l|c|c|c|c|c|c|c|c|c|c}
\hline CORPO V1 & $\mathrm{SiO}_{2}$ & $\mathrm{MgO}$ & $\mathrm{Fe}_{2} \mathrm{O}_{3}$ & $\mathrm{Al}_{2} \mathrm{O}_{3}$ & $\mathrm{Cr}_{2} \mathrm{O}_{3}$ & $\mathrm{MnO}_{2}$ & $\mathrm{NiO}$ & $\mathrm{CoO}$ & $\mathrm{CuO}$ & $\mathrm{PF}$ \\
\hline rocha fresca (n=3) & 33,18 & 35,93 & 11,69 & 1,05 & 1,36 & 0,10 & 0,33 & 0,01 & 0,00 & 14,40 \\
rocha parcialmente & & & & & & & & & & \\
alterada (n=7) & 36,43 & 31,17 & 13,86 & 1,66 & 0,80 & 0,16 & 0,64 & 0,02 & 0,01 & 15,73 \\
minério silicatado (n=12) & 35,64 & 22,07 & 24,82 & 1,71 & 1,13 & 0,21 & 1,78 & 0,03 & 0,01 & 13,39 \\
minério oxidado (n=11) & 11,34 & 3,36 & 65,74 & 3,85 & 2,98 & 0,96 & 1,71 & 0,16 & 0,02 & 9,40 \\
\hline \hline
\end{tabular}

parte média do minério oxidado, que possui, também, elevados teores de níquel.

\section{A ROCHA FRESCA A PARCIALMENTE ALTERADA}

Nas seções delgadas estudadas foi possível constatar a presença predominante de serpentina em diferentes gerações como descrito por Bernardelli et al. (1983). Uma primeira geração forma uma rede (geralmente em duas bandas de serpentina bem cristalizada, com finos grãos de magnetita no centro), em cujos núcleos observa-se serpentina menos bem cristalizada. As vezes há um entrelaçamento das serpentinas, e, nesse caso, não é possível uma distinção entre as duas gerações. Uma terceira geração de serpentina bem cristalizada, em veios, acompanhada por finos grãos de magnetita, e com cor de interferência mais alta dentro da mesma ordem, corta as demais. Mais raramente, podem ser observados veios de serpentina fibrosa, indicando a presença de crisotila e, mais próximo à borda do corpo em V1, bastitas formadas a partir de ortopiroxênio.

Bem menos freqüentes que as serpentinas, as cloritas aparecem como aglomerados irregulares, podendo formar uma rede cortando toda a rocha ou dispondo-se ao redor de cristais de cromita, ou ainda em cristais isolados. De modo geral, a rede de cloritas é posterior às varias gerações de serpentina, mas no corpo V1 foram observadas algumas cloritas cortadas ou sendo invadidas por serpentina. A associação forte da clorita com os espinélios é comum neste tipo de rocha, tendo sido referida por Boukili (1984) e Barbosa (1992) nas ultrabásicas de Campo Formoso, por Blais \& Auvray (1990) na serpentinização de komatiitos da Finlândia e por Oliveira \& Trescases (1980) em Santa Fé (GO). A alteração dos Cr-espinélios forneceria o alumínio necessário à formação da clorita.

Os Cr-espinélios não são abundantes, apresentando-se fraturados e, eventualmente, cortados por serpentina ou quartzo. Encontram-se cristais tanto euedrais, quanto subedrais e anedrais, sendo os dois últimos tipos mais freqüentes. Estes minerais podem também estar rodeados, além da clorita, por flogopita. A magnetita apresenta-se de modo geral em granulação muito fina, disseminada ou formando aglomerados e, mais raramente, veios. Em duas amostras de rocha fresca foi observada a presença de carbonatos; os difratogramas de raios X mostram um pico a 7,8 Â indicando tratar-se de um carbonato hidratado do tipo piroaurita.

O início da alteração intempérica destas rochas é marcado pela ferruginização das serpentinas que se tornam amareladas, e pela presença de material amorfo castanho, provavelmente de composição sílico-ferruginosa, entre as clivagens. Os aglomerados de magnetita mostram indícios de alteração também para o material amorfo castanho.
Algumas análises por microssonda eletrônica, que dão uma idéia da distribuição do níquel nos minerais constituintes do serpentinito fresco e parcialmente alterado (Tabela 2), mostraram que o níquel está mais concentrado nas serpentinas com um teor de $0,28 \% \mathrm{NiO}$ e, secundariamente, nas flogopitas. Nas cloritas foram encontrados teores variáveis entre 0 e $0,21 \% \mathrm{NiO}$. Na rocha parcialmente alterada, as serpentinas e as cloritas já são bem mais enriquecidas em média; dados para o espinélio indicam apenas $0,08 \% \mathrm{NiO}$

MINÉRIO SILICATADO O minério silicatado representa uma intensificação na alteração, que é acompanhada por um aumento nos teores de $\mathrm{NiO}$ da amostra total. Os teores da rocha fresca que estão em torno de $0,3 \%$ aumentam para valores da ordem de $2 \% \mathrm{NiO}$, quando se passa ao saprolito grosso. Os difratogramas de raios $\mathrm{X}$ de amostra total registram, neste nível, além de serpentina, espinélios, clorita e quartzo, a presença de goethita.

Da base para o topo do minério silicatado, a serpentina se dissolve, dando lugar a um produto amorfo sílico-ferruginoso. A dissolução age inicialmente sobre as serpentinas pior cristalizadas como já havia sido destacado por Bernardelli et ai (1983). Os veios da segunda geração, as bastitas e os veios de crisotila resistem mais tempo, começando a dissolver a partir da parte média do nível silicatado em direção ao topo, onde desaparecem. A diminuição no teor de magnésio é, portanto, resultado da dissolução das serpentinas, cujo desaparecimento marca o limite entre o minério silicatado e o oxidado.

Acompanhando as transformações das serpentinas, parte dos agrupamentos de magnetita altera-se em compostos

Tabela 2 - Distribuição do níquel entre as fases na rocha fresca e parcialmente alterada. Análises à microssonda eletrônica, $n=$ número de pontos e números entre parênteses $=$ intervalo de variação

Table 2 - Nickel distribution among the phases in fresh and partially altered rock. Electron microprobe analyses, $\mathrm{n}=$ number of points $=$ variation range

\begin{tabular}{l|c|c}
\hline & $\begin{array}{c}\text { rocha fresca } \\
\text { NiO\% }\end{array}$ & $\begin{array}{c}\text { rocha } \\
\text { parcialmente } \\
\text { alterada NiO\% }\end{array}$ \\
\hline $\begin{array}{l}\text { serpentina; } n=1 ; n=12 \\
\text { clorita; } n=7 ; n=29\end{array}$ & $\begin{array}{c}0,28 \\
0,09(0-0,21)\end{array}$ & $1,59(0,40-3,58)$ \\
$\begin{array}{l}\text { flogopitas; } n=10 \\
\text { espinélio; } n=5\end{array}$ & $\begin{array}{c}0,16(0,03-5,06,26) \\
\text { năo há dados }\end{array}$ & $\begin{array}{c}\text { ausente } \\
0,08(0-0,13)\end{array}$ \\
\hline
\end{tabular}


castanhos amorfos. Os contornos dos espinélios vão sendo corroídos e estes se tornam, progressivamente, mais fraturados, ao passo que um plasma goathítico alaranjado a avermelhado vai se desenvolvendo provavelmente às expensas dos produtos amorfos castanhos.

As cloritas são mais resistentes, apresentando apenas modificações nas características ópticas (há uma variação na coloração à luz polarizada que na rocha fresca é azulada e começa a se tornar amarelada, em direção ao topo deste nível), e podem apresentar sinais de dissolução.

Em alguns perfis há a destacar a presença de quartzo em veios ou preenchendo cavidades, puro ou associado à goethita.

A distribuição do níquel $\mathrm{O}$ enriquecimento em níquel no minério silicatado não é acompanhado pelo aparecimento de novas fases minerais que poderiam ser as portadoras deste elemento. As mudanças nas características ópticas de alguns minerais presentes, serpentinas e cloritas, indicam mudanças na composição química.

$\mathrm{O}$ estudo da distribuição do níquel e outros elementos foi efetuado com microscópio eletrônico de varredura, através do programa de cartografia de elementos. As imagens obtidas (Foto 1) não mostram concentrações preferenciais do níquel, que está distribuído entre as serpentinas e cloritas e, provavelmente, nos produtos amorfos e plasma goethítico. Análises químicas pontuais efetuadas com microssonda eletrônica ou EDS acoplado ao MEV mostram os teores de níquel nas diferentes fases minerais (Tabela 3). Embora os valores máximos sejam encontrados na clorita, a serpentina tem, em média, mais níquel. Essa observação deve, porém, ser relativizada pelo fato da média, no caso das serpentinas, basear-se apenas em três análises, ao passo que a da clorita representa 25 análises. Dessa forma, os resultados obtidos permitem apenas dizer que os teores de níquel nos dois minerais estão dentro da mesma faixa de variação.

Os minerais portadores de níquel Foram efetuadas análises químicas por microssonda eletrônica em cloritas e serpentinas. As fórmulas estruturais das cloritas calculadas
Tabela 3 - Teores médios de $\mathrm{NiO}$ (\% em peso) nas fases do minério silicatado. Análises à microssonda eletrônica ou $M E V-E D S^{*}$ (n-número de pontos)

Table 3 - Mean NiO (wt\%) contents in different phases of the silicated ore. Electron-microprobe or EDS-SEM* analyses ( $n=$ number of points)

\begin{tabular}{l|c|c|c}
\hline & $\begin{array}{c}\text { NiO\% } \\
\text { média }\end{array}$ & $\begin{array}{c}\text { NiO\% } \\
\text { máximo }\end{array}$ & $\begin{array}{c}\text { NiO\% } \\
\text { mínimo }\end{array}$ \\
\hline clorita $(n=25)$ & 2,45 & 5,22 & 0,57 \\
serpentina $(n=3)$ & 3,11 & 3,97 & 1,39 \\
espinélio $(n=8)$ & 0,12 & 0,33 & 0 \\
amorfos $(n=1)^{*}$ & 1,60 & & \\
\hline
\end{tabular}

na base de 14 oxigênios estão na Tabela 4 e mostram tratarse de cloritas magnesianas. As diferenças entre as amostras analisadas relacionam-se aos teores de níquel, alumínio e magnésio, sugerindo substituições entre esses elementos. As cloritas de V2, expressivamente mais enriquecidas em níquel, são também mais magnesianas e menos aluminosas do que as do corpo VI.

No caso das serpentinas, poucas análises de cada amostra foram efetuadas e não foi possível estudar as variações ocorridas durante o processo de dissolução. As fórmulas estruturais médias das amostras analisadas estão na Tabela 5. Deve-se ressaltar que as análises que deram origem a estas médias podem provir de diferentes tipos de serpentinas. Muitas análises foram descartadas em função do baixo total obtido devido, provavelmente, ao fato $\mathrm{de}^{\wedge} \mathrm{OS}$ minerais estarem já alterados, parcialmente dissolvidos. É interessante ressaltar que composições intermediárias entre serpentinas e cloritas foram encontradas em pontos no contato entre os dois minerais, sugerindo passagem de uma fase a outra.

Uma distinção entre os minerais da família das serpentinas é bastante difícil do ponto de vista químico, sendo usualmente utilizadas para diagnóstico as texturas e o aspecto morfológico dos cristais observados ao microscópio eletrônico de transmissão. No entanto, Boukili (1984) e

Tabela 4-Minério silicatado: fórmulas estruturais de cloritas (base 14 O). Análises por microssonda eletrônica. As amostras de 1 a 5 são provenientes de V2 e de 6 a 9 de V1

Table 4 - Silicated ore: structural formulae of chlorites on 14(O) basis. Electron-microprobe analyses. Samples 1 to 5 from V2 and samples 6 to 9 from VI

\begin{tabular}{|c|c|c|c|c|c|c|c|c|c|}
\hline & 1 & 2 & 3 & 4 & 5 & 6 & 7 & 8 & 9 \\
\hline $\mathbf{S i}$ & 3,34 & 3,28 & 3,34 & 3,49 & 3,32 & 3,80 & 3,89 & 3,62 & 3,34 \\
\hline $\begin{array}{l}\mathrm{Al}^{\mathrm{lV}} \\
\mathrm{R}^{2+}\end{array}$ & 0,66 & 0,72 & 0,66 & 0,51 & 0,68 & 0,20 & 0,11 & 0,38 & 0,66 \\
\hline $\mathrm{Mg}$ & 4,35 & 4,50 & 4,36 & 4,64 & 4,63 & 4,01 & 3,74 & 3,87 & 4,27 \\
\hline $\mathrm{Ni}$ & 0.22 & 0,12 & 0.24 & 0.16 & 0,07 & 0,03 & 0,05 & 0,08 & 0,03 \\
\hline $\mathrm{Fe}$ & 0,40 & 0,39 & 0,43 & 0,35 & 0,37 & 0,39 & 0,32 & 0,30 & 0,25 \\
\hline $\mathrm{Mn}$ & 0,00 & 0,00 & 0,01 & 0,00 & 0,01 & 0,00 & 0,01 & 0.01 & 0,00 \\
\hline Co & 0,01 & 0,00 & 0,01 & 0,01 & 0,00 & 0,00 & 0,00 & 0,00 & 0,00 \\
\hline $\mathrm{Ca}$ & 0,02 & 0,01 & 0,01 & 0,01 & 0,01 & 0,02 & 0,05 & 0,04 & 0,04 \\
\hline $\mathrm{R}^{+}$ & & & & & & & & & \\
\hline $\mathrm{Na}$ & 0,03 & 0,03 & 0,03 & 0,02 & 0,02 & 0,03 & 0,04 & 0,05 & 0,04 \\
\hline$\underset{\mathbf{R}^{3+}}{\mathbf{K}}$ & 0,01 & 0,02 & 0,02 & 0,03 & 0,03 & 0,04 & 0,02 & 0,02 & 0,04 \\
\hline$A I^{\mathrm{VI}}$ & 0,72 & 0,74 & 0,62 & 0,56 & 0,63 & 0,89 & 1,10 & 1,09 & 0,70 \\
\hline $\begin{array}{c}\mathrm{Cr} \\
\mathrm{R}^{4+}\end{array}$ & 0,02 & 0,00 & 0,05 & 0,03 & 0,04 & 0,02 & 0,02 & 0,02 & 0,02 \\
\hline $\mathbf{T i}$ & 0,01 & 0,00 & 0,02 & 0,01 & 0,02 & 0,01 & 0,01 & 0,03 & 0,02 \\
\hline 0,23 & 0,19 & 0,21 & 0.19 & 0,17 & 0.53 & 0,65 & 0.51 & 0.13 & \\
\hline
\end{tabular}



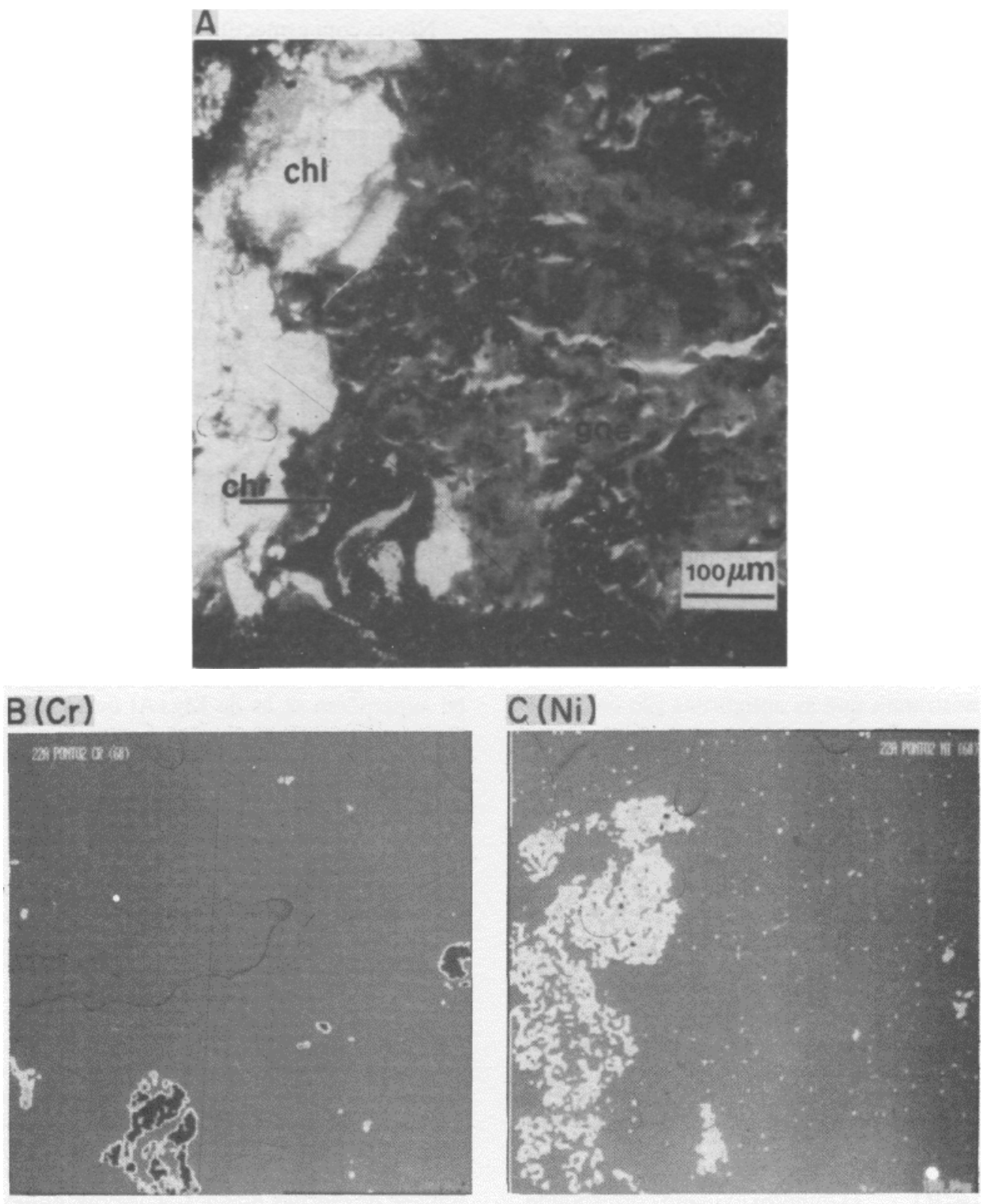

\section{$\mathrm{D}(\mathrm{Mg})$}

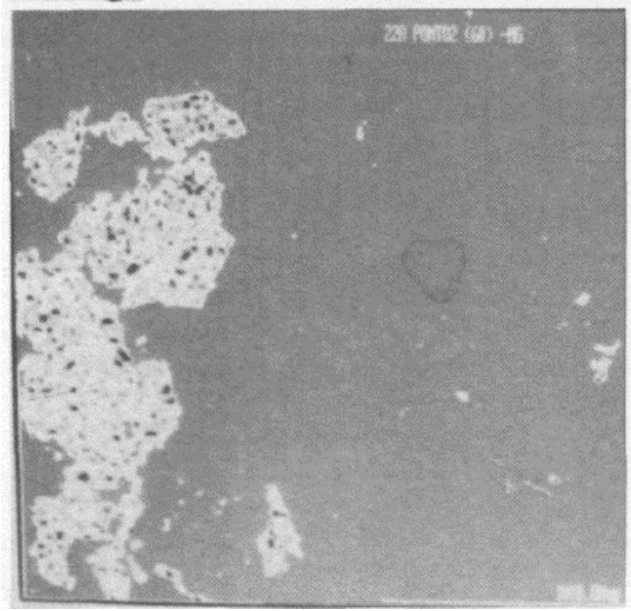

\section{$E(A \mid)$}

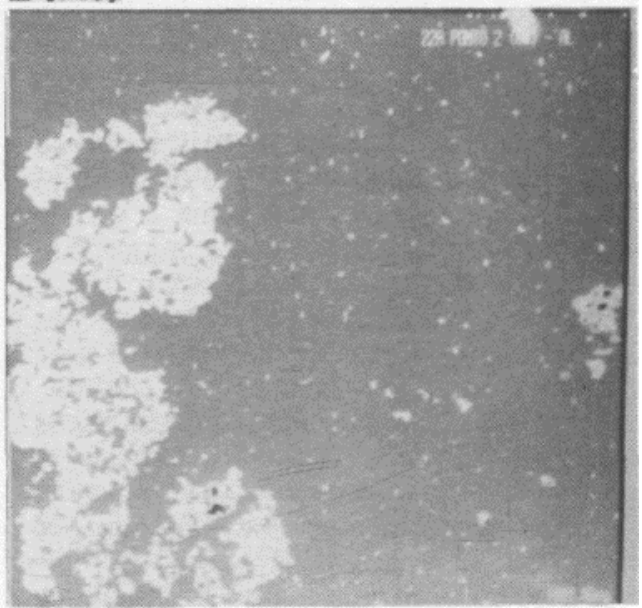

Foto 1 - Distribuição de Al, Cr, Ni e Mg no minério silicatado (cr=cromila; $p l=$ plasma; se=serpentina; $c l$-cloriia). A = fotomicrografia com luz polarizada. B - imagens de cartografia de elementos obtida com MEV

Photo 1 - $\mathrm{Al}, \mathrm{Cr}, \mathrm{Ni}$ and $\mathrm{Mg}$ distribution in the silicated ore $(\mathrm{cr}=$ chromite, $\mathrm{pi}=$ plasma; $\mathrm{se}=$ serpentine; $\mathrm{cl}=\mathrm{chlorite}) . \mathrm{A}=$ photomicrograph with plane polarized light. $\mathrm{B}=\mathrm{SEM}$ images of elemental mapping 
Tabela 5 - Minério silicatado: fórmulas estruturais de serpentinas (base 7 O). Análises à microssonda eletrônica. As amostras de 1 a 3 são provenientes de V2 e as amostras 4 e 5 de $V 1$

Table 5 - Silicated ore: structural formulae of serpentines on 7(O) basis. Electron microprobe analyses. Samples 1 to 3 from V2 and samples 4 and 5 from V1

\begin{tabular}{c|c|c|c|c|c}
\hline & 1 & 2 & 3 & 4 & 5 \\
\hline $\mathrm{Si}^{\mathrm{I}}$ & 1,93 & 2,04 & 1,98 & 1,98 & 2,31 \\
$\mathrm{Al}^{\mathrm{v}}$ & 0,05 & & 0,02 & 0,01 & \\
$\mathrm{Fe}^{\mathrm{v}}$ & 0,02 & 0,01 & & & \\
$\mathrm{Al}^{\mathrm{v}}$ & - & 0,04 & 0,01 & - & 0,02 \\
$\mathrm{Fe}^{\mathrm{v}}$ & 0,22 & 0,16 & 0,25 & 0,08 & 0,28 \\
$\mathrm{Na}$ & 0,01 & 0,02 & 0,01 & 0,00 & 0,03 \\
$\mathrm{Mg}$ & 2,56 & 2,42 & 2,55 & 2,87 & 1,84 \\
$\mathrm{Mn}$ & 0,00 & 0,00 & 0,00 & 0,00 & 0,00 \\
$\mathrm{Co}$ & 0,00 & 0,00 & 0,01 & 0,00 & 0,00 \\
$\mathrm{Ni}$ & 0,07 & 0,16 & 0,06 & $\mathbf{0 , 0 1}$ & 0,02 \\
$\mathbf{K}$ & 0,00 & 0,01 & 0,00 & 0,00 & 0,01 \\
$\mathrm{Ca}$ & 0,00 & 0,00 & 0,00 & 0,00 & 0,03 \\
$\mathrm{Ti}$ & 0,01 & 0,00 & 0,00 & 0,00 & 0,00 \\
$\mathrm{Cr}$ & 0,03 & 0,00 & 0,00 & 0,00 & 0,02 \\
\hline
\end{tabular}

Barbosa (1992) mostraram que as antigoritas são em geral mais ricas em alumínio do que lizarditas e crisotilas, sendo a distinção química entre essas duas espécies muito mais difícil. Os resultados químicos e as texturas observadas permitem dizer que, provavelmente, estes três tipos de minerais estão presentes na jazida de níquel do Vermelho. As análises efetuadas em amostras do corpo V1 são quase desprovidas de alumínio, correspondendo possivelmente a análises de lizarditas, posto que não foram efetuadas nos veios cujo aspecto fibroso caracterizaram a presença de crisotila. Já as provenientes de amostras do corpo V2 apresjentam teor de alumínio compatível com o das antigoritas. $\mathrm{E}$ interessante ressaltar que estas serpentinas mais ricas em alumínio são também mais ricas em níquel e mais pobres em ferro (Tabela 5). Além disso, pode-se observar um alto teor de silica nessas serpentinas, semelhante ao encontrado nas serpentinas de Campo Formoso (Barbosa 1992 e Boukili 1984).

MINÉRIO OXIDADO O minério oxidado corresponde a uma fase de laterização mais intensa, e a passagem entre este e o nível subjacente é, em geral, relativamente brusca. Com o desaparecimento da serpentina, o minério oxidado passa a ser constituído por um plasma vermelho amarelado, com magnetita fina dispersa, no qual foram encontradas cloritas e restos de cromitas. Da base para o topo desse nível, as cloritas apresentam intensificação dos sinais de dissolução e mudança nas características ópticas, com a cor de interferência passando em geral de amarelada a branca. Em direção à superfície, os opacos, devido à sua maior resistência à alteração, estão mais concentrados e sofrem apenas uma ligeira alteração que leva ao desenvolvimento de uma película fina goethítica ou amorfa, circundando os cristais. Os difratogramas de raios $\mathrm{X}$ e os estudos petrográficos indicaram a presença de goethita, espinélio, cloritas e, eventualmente, quartzo. Assim, pode-se dizer que o plasma vermelho amarelado é constituído essencialmente por goethita. Na verdade, trata-se de um plasma sílico-ferruginoso, pois observações ao MEV mostram através de estudos com grande aumento, pequenas concentrações de silica, provavelmente amorfa, dispersas neste plasma. Este fato é confirmado pelas análises quantitativas pontuais por EDSMEV que sempre detectam porcentagens de silica nas análises do plasma, em média $16 \% \mathrm{SiO}_{2}$.
Níveis com esmectita aparecem intercalados no saprolito fino, em aparente discordância com a tendência geral da evolução. Correspondem provavelmente a descontinuidades na rocha-mãe, como veios de piroxenito ou peridotito cortando o serpentinito. Feição semelhante foi descrita por Colin (1990) no perfil de Angiquinho, Niquelândia (GO). Nesses níveis com esmectita, persiste a clorita, o plasma é mais avermelhado e aparecem bolsões macroscópicos de quartzo.

Em algumas partes do minério oxidado a silicificação é bastante intensa (silcrete). Nesses casos, o minério é cortado por uma rede de finos veios de quartzo microcristalino, com grãos que podem estar envolvidos por fina película ferruginosa, em cujo interior encontra-se o plasma goethítico. A clorita também pode estar presente associada aos veios ou no plasma com quartzo no meio das lamelas.

A distribuição do níquel No minério oxidado, temos o predomínio da goethita, a qual é usualmente considerada como a principal portadora de níquel. Estudos por cartografia de elementos efetuada ao MEV mostraram que, além de presente no plasma goethítico, o níquel está fortemente concentrado nas cloritas e ausente nas cromitas e magnetitas. A Foto 2 mostra as imagens de distribuição de $\mathrm{Cr}, \mathrm{Ni}, \mathrm{Mg}$ e Al comparadas com a fotomicrografia da mesma região. Verifica-se que as maiores concentrações de $\mathrm{Ni}$ superpõ̃em-se às de $\mathrm{Mg}+\mathrm{Al}$ que são os elementos que, juntos, delimitam as cloritas. Comparando-se as imagens de distribuição de $\mathrm{Cr}$ e Ni, constata-se onde o cromo está concentrado, i. é., nas cromitas, o níquel está ausente. Análises químicas pontuais foram efetuadas por EDS-MEV e por microssonda eletrônica e uma síntese dos resultados é apresentada na Tabela 6 . A concentração de níquel nas cloritas é, em média, da ordem de $12 \% \mathrm{NiO}$, enquanto no plasma e na goethita os valores estão por volta de $! \% \mathrm{NiO}$. Nos níveis onde a esmectita está presente, verifica-se que esses minerais podem conter quantidades de níquel semelhantes às das cloritas.

As fases minerais portadoras de níquel Dentre as fases minerais portadoras de níquel, as cloritas, esmectitas e goethitas foram estudadas em detalhe. $\mathrm{Na}$ Tabela 7 são apresentadas as fórmulas estruturais de diferentes amostras de cloritas calculadas na base de 14 oxigênios, e ferro como Fe 3+. A exemplo das do nível silicatado, trata-se de cloritas magnesianas pois, embora mais ricas em níquel, é ainda o magnésio o principal cation a ocupar posiçōes octaédricas. A composição da camada tetraédrica é aproximadamente constante e as variações se dão principalmente entre $\mathrm{Ni}, \mathrm{Mg}$ e Al nas camadas octaédricas e são mais importantes do que no minério silicatado.

Tabela 6 - Distribuição do níquel nas principais fases do minério oxidado $\left(^{1}\right)$ análises por microssonda eletrônica; $\left.{ }^{2}\right)$ análises ao MEV-EDS; $n$ - número de pontos) Table 6: Nickel distribution among the principal phases of the oxidized ore $\left({ }^{1}\right)$ electron-microprobe analyses; $\left.{ }^{2}\right)$ EDS-SEM analyses; $n=$ number of points)

\begin{tabular}{l|c|c|c}
\hline & $\begin{array}{c}\text { NiO\% } \\
\text { média }\end{array}$ & $\begin{array}{c}\text { NiO\% } \\
\text { máximo }\end{array}$ & $\begin{array}{c}\text { NiO\% } \\
\text { mínimo }\end{array}$ \\
\hline clorital $(n=87)_{\text {plasma }^{2}(n=28)}$ & 11,70 & 15,95 & 8,80 \\
goethita $^{1}(n=16)$ & 0,96 & 2,71 & 0,19 \\
Cr-espinelio $^{2}(n=2)$ & 1,28 & 1,75 & 0,93 \\
esmectita $(n=12)$ & 0,30 & 0,37 & 0,23 \\
\hline
\end{tabular}



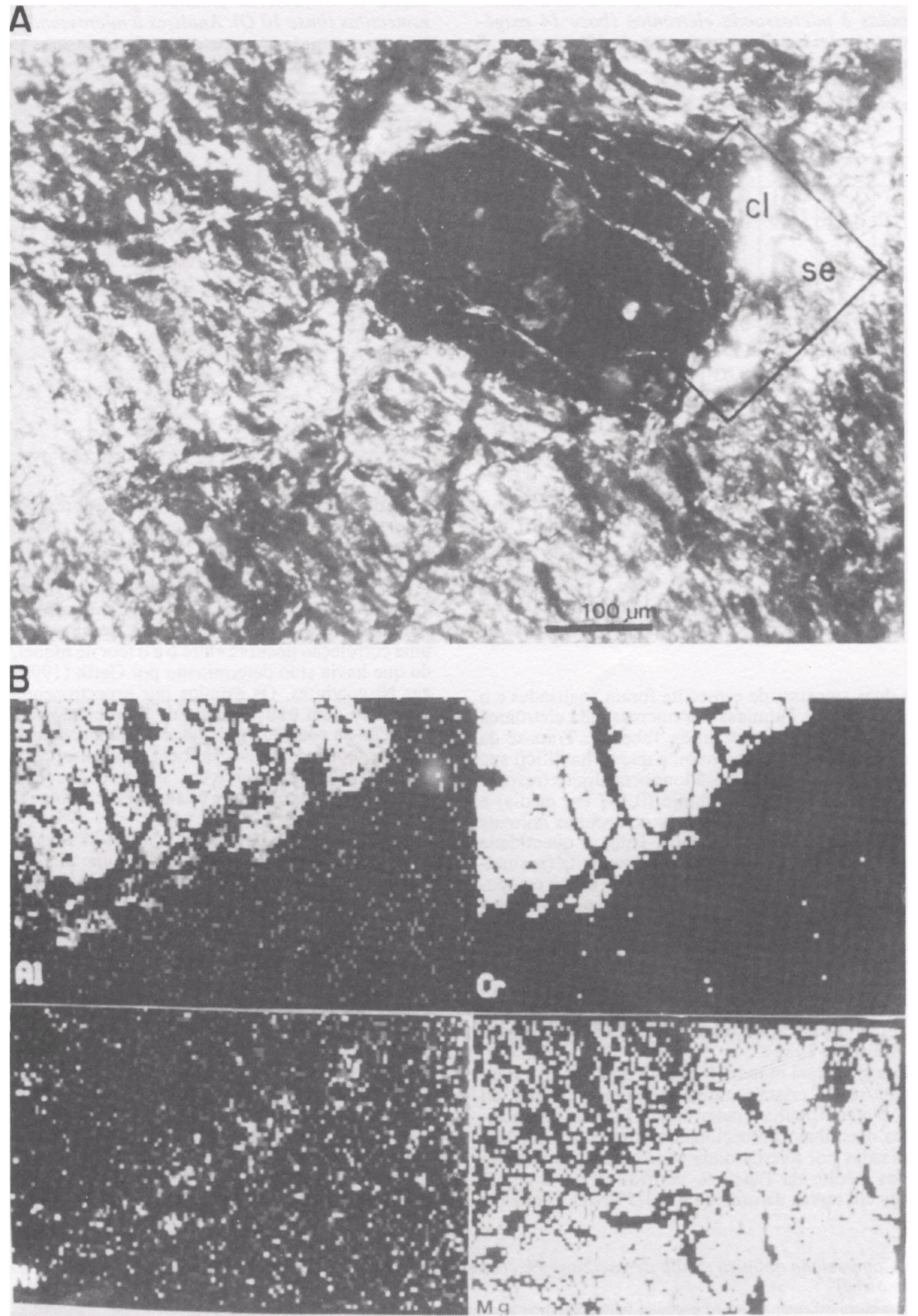

Foto 2 - Distribuição de $\mathrm{Cr}, \mathrm{Ni}, \mathrm{Mg}$ e Al no minério oxidado (chl=clorita; goe=plasma goethítico; chr=chromita). $A=$ fotomicrografia com luz polarizada. $B$ a $E$ = imagens de cartografia de elementos obtida com MEV

Photo $2-\mathrm{Cr}, \mathrm{Ni}, \mathrm{Mg}$ and $\mathrm{Al}$ in the oxidized ore $(\mathrm{cr}=$ chromite, $\mathrm{pi}=$ plasma; $\mathrm{se}=$ serpentine; $\mathrm{cl}=$ chlorite $)$. $\mathrm{A}=$ photomicrograph with plane polarized light. $\mathrm{B}$ to $\mathrm{E}=\mathrm{SEM}$ images of elemental mapping 
Tabela 7 - Minério oxidado: fórmulas estruturais de cloritas analisadas à microssonda eletrônica (base 14 oxigênios). Amostras de 1 a 7 provenientes de V2, amostra 8 proveniente de VI

Table 7 - Oxidized ore: structural formulae of chlorites on 14(O) basis calculated from electron microprobe data. Samples 1 to 7 from V2, sample 8 from V1

\begin{tabular}{|c|c|c|c|c|c|c|c|c|}
\hline & 1 & 2 & 3 & $\overline{4}$ & 5 & $\overline{6}$ & 7 & 8 \\
\hline$\overline{S i}$ & 3,43 & 3,93 & 3,51 & 3,46 & 3,33 & 3,36 & 3,26 & 3,24 \\
\hline $\begin{array}{c}\mathrm{Al}^{\mathrm{IV}} \\
\mathrm{R}^{2+}\end{array}$ & 0,57 & 0,07 & 0,49 & 0,54 & 0,67 & 0,64 & 0,74 & 0,76 \\
\hline $\mathrm{Mg}$ & 2,70 & 2,36 & 2,92 & 2,78 & 2,69 & 3,66 & 3,03 & 3,75 \\
\hline $\mathbf{N i}$ & 1,07 & 0,83 & 1,12 & 0,93 & 0,71 & 0,70 & 1,32 & 0,71 \\
\hline Mn & 0,00 & 0,02 & 0,00 & 0,00 & 0,01 & 0,00 & 0,01 & 0,00 \\
\hline Co & 0,03 & 03 & 0,03 & 0,02 & 0,01 & 0,01 & 0,02 & 0,01 \\
\hline $\begin{array}{l}\mathrm{Ca} \\
\mathrm{R}^{+}\end{array}$ & 0,01 & 0,04 & 0,01 & 0,03 & 0,02 & 0,02 & 0,00 & 0,04 \\
\hline $\mathrm{Na}$ & 0,01 & $\mid 0,01$ & 0,02 & 0,05 & 0,03 & 0,00 & 0,00 & 0,04 \\
\hline $\begin{array}{c}\mathbf{K} \\
\mathbf{R}^{3+}\end{array}$ & 0,00 & 0,03 & 0,01 & 0,03 & 0,03 & 0,01 & 0,00 & 0,01 \\
\hline $\mathrm{Fe}$ & 0,36 & 0,69 & 0,44 & 0,35 & 0,28 & 0,35 & 0,31 & 0,28 \\
\hline $\mathrm{Al}^{\mathrm{vI}}$ & 1,15 & 1,03 & 0,91 & 1,24 & 1,60 & 0,90 & 0,94 & 0,90 \\
\hline $\begin{array}{l}\mathrm{Cr} \\
\mathrm{R}^{4+}\end{array}$ & 0,07 & 0,04 & 0,03 & 0,02 & 0,02 & 0,02 & 0,03 & 0,92 \\
\hline $\mathbf{T i}$ & 0,04 & 0,03 & 0,04 & 0,03 & 0,00 & 0,01 & 0,03 & 0,02 \\
\hline - & 0,55 & 0,90 & 0,47 & 0,54 & 0,59 & 0,32 & 0,30 & 0,22 \\
\hline
\end{tabular}

Apenas duas amostras de esmectita foram analisadas e 0 resultado das análises químicas por microssonda eletrônica e as fó rmulas estruturais constam da Tabela 8. Trata-se de uma esmectita de fó rmula incomum, e que torna difícil sua classificação. Há um excesso de cations octaédricos (respectivamente 2,5 e 2,3), pouco alumínio $(0,177$ em media) e alto magné sio $(1,048)$, com relação às nontronitas normais (Weaver \& Polard, 1973). Por outro lado, a quantidade de $\mathrm{R} 3+$ é muito alta $(0,75-0,85)$ para uma saponita (normalmente $<0,50)$, embora os conteú dos de Al e Fe sejam compatíveis com uma natureza saponítica. Os cations bivalentes correspondem a $67 \%$ e $67,5 \%$ dos cations octaédricos, o que é baixo para uma esmectita trioctaédrica, mas compatível com as dioctaédricas. Essas esmectitas niquelíferas sã 0 , possivelmente, minerais de natureza mista, di-trioctaé dricos. Os difratogramas de raios X mostram o pico (060) a $1,51 \AA$ o que é indicativo de esmectitas di-trioctaédrica (Brindley \& Brown 1980).

A goethita, principal mineral formador do minério oxidado, apresenta-se em cristais muito pequenos, menores do que $100 \AA$, 0 que dificulta a determinação de sua composição química. Pastilhas confeccionadas com pó de goethita foram analisadas por microssonda eletrônica e forneceram os resultados médios da Tabela 9. Verifica-se que o níquel está presente em teores da ordem de $1-1,5 \% \mathrm{NiO}$. Os teores
Tabela 8 - Minério oxidado: fórmulas estruturais de esmectitas (base $10 \mathrm{O}$ ). Analises à microssonda eletrônica Table 8 - Oxidized ore: structural formulae of smectites on 10(0) basis. Electron-microprobe analyses

\begin{tabular}{l|c|c}
\hline & 1 & 2 \\
\hline $\mathrm{Si}$ & 3,95 & 3,99 \\
$\mathrm{Al}^{\mathrm{wv}}$ & 0,05 & 0,01 \\
$\mathrm{Mg}$ & 1,12 & 0,98 \\
$\mathrm{Fe}^{3+}$ & 0,82 & 0,50 \\
$\mathrm{Ni}$ & 0,55 & 0,58 \\
$\mathrm{Al}$ & 0,08 & 0,27 \\
$\mathrm{Mn}$ & 0,00 & 0,01 \\
$\mathrm{Co}$ & 0,00 & 0,00 \\
$\mathrm{Ti}$ & 0,00 & 0,01 \\
$\mathrm{Cr}$ & 0,00 & 0,01 \\
$\mathrm{Na}$ & 0,02 & 0,26 \\
$\mathrm{Ca}$ & 0,05 & 0,14 \\
$\mathrm{~K}$ & 0,02 & 0,02 \\
\hline
\end{tabular}

de silica podem estar relacionados à presença de silica amorfa verificada nos estudos por MEV, ou ainda serem devidos à s substituiçõ es de $\mathrm{Fe} 3+$ por Si4t. A determinacão dos parâmetros cristalográficos, efetuada a partir de difratogramas de raios $X$ de goethitas puras, mostrou que há variação nos valores de a b, c e, conseqü entemente, do volume com a variação dos teores de níquel. Verificou-se uma correlaçã o positiva entre b e o teor de níquel, a exemplo do que havia sido determinado por Gerth (1990) ao sintetizar Ni-goethitas. Os estudos por espectroscopia do infravermelho com transformada de Fourier mostraram que há variação na posição das bandas de ressonância com a variação dos teores de níquel. Embora esses resultados não sejam conclusivos, essas variações sugerem que o níquel pode estar presente na estrutura cristalina desse mineral, em substituição ao ferro.

Acompanhando os bolsõ es e veios de quartzo, há ainda a destacar a presença de talco, cuja análise ao EDSMEV mostrou ser niquelífero, embora pela falta de dados quantitativos não se saiba em que proporção 0 níquel está presente.

CONSIDERAC Õ ES FINAIS Como os minérios lateríticos em geral, també m o minério do Vermelho é complexo, pois 0 níquel se associa a diferentes fases minerais, em diferentes concentraçõ es, tanto no miné rio silicatado, quanto no oxidado. Assim é que os teores médios encontrados no miné rio silicatado devem-se, principalmente, à serpentina enriquecida em níquel, que é 0 mineral predominante, às cloritas que também contêm níquel e ao plasma sílicoferruginoso que se forma a partir da alteração das serpentinas. Nessas fases o teor de níquel está principalmente entre 2 - $3 \% \mathrm{NiO}$ (serpentinas e cloritas) e $1,5 \%$ (plasma). 0 níquel ocorre substituindo o magné sio nas cavidades octaédricas

Tabela 9 - Composição química mé dia de goethitas (\% em peso) analisadas por microssonda eletrônica (5 pontos analisados em cada amostra)

Table 9 - Mean chemical composition of goethites (wt\%). Electron-microprobe analyses ( 5 points for each sample)

\begin{tabular}{c|c|c|c|c|c|c|c|c|c|c|c|c|c}
\hline & $\mathrm{Na}_{2} \mathrm{O}$ & $\mathrm{MgO}$ & $\mathrm{Al}_{2} \mathrm{O}_{3}$ & $\mathrm{SiO}_{2}$ & $\mathrm{~K}_{2} \mathrm{O}$ & $\mathrm{CaO}$ & $\mathrm{TiO}_{2}$ & $\mathrm{C}_{2} \mathrm{O}_{3}$ & $\mathrm{MnO}$ & $\mathrm{FeO}$ & $\mathrm{CoO}$ & $\mathrm{NiO}$ & total \\
\hline $\mathrm{l}$ & 0.09 & 0.93 & 2.86 & 4.07 & 0.01 & 0.00 & 0.09 & 0.69 & 0.63 & 65.40 & 0.15 & 1.63 & 76.56 \\
2 & 0.05 & 0.22 & 3.55 & 5.83 & 0.03 & 0.05 & 0.13 & 0.56 & 0.43 & 62.59 & 0.06 & 1.08 & 74.57 \\
3 & 0.05 & 0.21 & 3.04 & 5.44 & 0.01 & 0.08 & 0.12 & 0.42 & 0.38 & 63.58 & 0.10 & 1.10 & 74.54 \\
\hline
\end{tabular}


das serpentinas e, provavelmente, também substituindo o magnésio nas cavidades octaédricas da camada 2:1 das cloritas. Os Cr-espinélios e as magnetitas, além de quartzo em veios eventualmente presentes, são desprovidos de níquel. A proporção relativa entre os minerais estéreis e niquelíferos fornecerá os teores médios variáveis encontrados neste tipo de minério.

No minério oxidado, embora a constituição mineralógica seja mais simples, a variação nos teores de níquel incorporados pelas diferentes fases minerais é maior do que no minério silicatado. Nestes níveis, as fases portadoras de níquel são as goethitas do plasma goethítico e as cloritas. Ás goethitas são a fase mineral mais abundante, e seus teores variam entre 0,9 e $1,7 \% \mathrm{NiO}$. As cloritas, embora sejam menos abundantes, concentram muito níquel, atingindo teores de 8 a $15 \%$. Portanto, o papel das cloritas na composição do teor médio do minério oxidado é importante, apesar de sua menor abundância com relação à goethita. Assim, o minério oxidado do corpo V2 apresenta teores médios em níquel mais altos que os do corpo $\mathrm{V} 1$, onde as cloritas são menos abundantes. Dessa forma, também no caso do minério oxidado, a quantidade relativa das fases minerais estéreis e niquelíferas é importante na composição dos teores médios.

Nos níveis superiores do minério oxidado um início de fenômeno de iluviação e compactação leva a um acúmulo de opacos, que são fases minerais estéreis com relação ao níquel, fazendo com que haja uma maior diluição dos teores desse elemento.

Um nível intercalado no minério oxidado, com teores excepcionais de níquel, às vezes está presente nos perfis. Sua distribuição espacial, no entanto, é desconhecida. Neste nível foram identificadas, além de cloritas, esmectitas niquelíferas com teores por volta de $8 \% \mathrm{NiO}$. Há ainda a destacar a presença de talco niquelífero (teores não determinados), mal cristalizado, característicamente de neoformação que aparece envolvendo os cristais de quartzo concentrados em bolsões, conferindo-lhes a cor verde característica do crisoprásio. Neste nível, mais pobre em opacos, a presença de mais fases portadoras de níquel, esmectitas, cloritas e talco, pode explicar os altos teores encontrados,

A persistente presença da clorita de origem hipógena ao longo de praticamente todo o perfil de alteração, exceto nos seus níveis superiores representados pela laterita vermelha, é uma peculiaridade do depósito do Vermelho. Em alguns outros depósitos lateríticos de níquel como Niquelândia (Colin 1984), Liberdade (Esson \& Santos 1978), Morro do Níquel (Brindley \& Souza 1975) e Nova Caledonia (Trescases 1975), a clorita também está presente na rocha fresca ou no perfil de alteração, porém é restrita a determinados horizontes no perfil. Uma explicação para sua estabilidade excepcional num ambiente laterítico, como no Vermelho, pode ser exatamente a incorporação do níquel disponível em substituição ao magnésio liberado à medida que as cloritas se alteram. Zeissink (1969) registra também a presença de cloritas ao longo de praticamente todo o perfil de alteração em depósito niquelífero laterítico da Austrália; esses minerais, embora apresentem semelhanças com as cloritas do Vermelho, não são niquelíferos. O autor sugere que a estabilidade destes minerais no perfil seja devida à presença de cromo na estrutura cristalina da clorita, embora não tenham sido efetuados estudos de detalhe.

Com relação às esmectitas, são reconhecidas três possibilidades para sua formação num perfil laterítico sobre rochas ultramáficas: alteração das olivinas em condições de drenagem restrita no início da alteração (por exemplo em Santa Fé, Oliveira 1980), alteração da serpentina em condições climáticas semi-áridas (caso de São João do Piauí, Terscases et al. 1986), ou então alteração de piroxênios (em Jacuba, Niquelândia, Colin et al. 1985). Independente de sua gênese, as esmectitas poderão absorver níquel, se este elemento estiver disponível. No Vermelho, foram detectados dois tipos de esmectitas. As estudadas neste trabalho, niquelíferas, são provavelmente provenientes da alteração dos piroxênios dos níveis piroxeníticos intercalados nos dunitos serpentinizados, e que se enriquecem por incorporação do níquel proveniente dos horizontes superiores do perfil, evoluídos a partir dos dunitos serpentinizados. Corrêa et al. (1984) referem-se a um nível esmectítico niquelífero espesso, cuja origem é provavelmente semelhante ao nível portador das esmectitas estudadas neste trabalho. Há, ainda, esmectitas nos perfis desenvolvidos a partir de lentes de piroxenitos, em fundos de vales suspensos, que são estéreis. Em Niquelândia, em situação semelhante, os perfis são enriquecidos em níquel devido à migração lateral (Oliveira \& Trescases 1982), enquanto no Vermelho, devido ao desenvolvimento essencialmente vertical do perfil, esta migração lateral não ocorre.

Em síntese, dois tipos de fases minerais portadoras de níquel foram determinadas no minério laterítico de níquel do Vermelho. Um constituído por minerais que mantêm um arcabouço estrutural essencialmente hipógeno, embora sua composição química se modifique à medida que incorpora níquel durante sua alteração: serpentinas e cloritas. Outro, por fases minerais neoformadas, goethita principalmente, mas também esmectitas e talco essencialmente supérgenos.

Agradecimentos As autoras agradecem à CAPES e ao $\mathrm{CNPq}$ pela bolsa de doutoramento concedida à primeira autora e à FAPESP pelo auxílio utilizado na finalização do trabalho. São também reconhecidas à Rio Doce Geologia e Mineração S/A - DOCEGEO pelo envio das amostras e aos pesquisadores do Laboratório "Argiles, Sols et Alterations" da Universidade de Poitiers e do Centro de Bondy ORSTOM, pelas facilidades analíticas. Os revisores anônimos contribuíram para a melhoria do texto final.

\section{REFERÊNCIAS BIBLIOGRÁFICAS}

ALVES, C. A.; BERNARDELLI, A. L \& BEISIEGEL, V. R. 1986. A jazida de níquel laterítico do Vermelho, serra dos Carajás, Pará In: Schobbenhaus, C.R. \& Coelho, C.E.S. (Coords.). Principais Depósitos Minerais do Brasil. Rio de Janeiro, DNPM.. v.2, p. 325-340

BERNARDELLI, A. L.; MELFI, A. J.; OLIVEIRA, S. M. B. de. \& TRESCASES, J.J. 1983. The Carajás nickel deposit. In: MELFI, A. J. \& CARVALHO, A. (eds). Laterisation processes: Proceedings at the II Int. Sem. on Laterisation Processes. São Paulo, IAG. p. 107-118.

BARBOSA, R. M. 1992. Evolução geoquímica e mineralógica da cobertura de alteração das rochas cromíferas de Campo Formoso (Mina Coitezeiro): Comportamento do cromo nas alterações hidrotermais e supérgena. São Paulo, 161 p. (Tese de Doutoramento., Instituto de Geociências, USP).
BLAIS, S. \& AUVRAY, B. 1990. Serpentinization in the archean komatiitic rocks of the Kuhmo greenstone belt, eastern Finland. Can. Mineralogist, 28(1):55-66.

BOUKILI, H. 1984. Pétrologie, minéralogie et géochimie des alterations des roches ultrabasiques à chromites de Campo Formoso, Brésil. Strasbourg, These 3ème cycle, Université de Strasbourg, $130 \mathrm{p}$.

BRINDLEY, G.W. \& SOUZA, J. V. de 1975. A golden-coloured, ferrinickel chlorite from Morro do Níquel, Minas Gerais, Brasil. Clays and Clay Min., 23:11-15.

BRINDLEY. G.W. \& BROWN, G. 1980. Crystal structures of clay and their X-ray identification. Mineral. Mag., London. 495p.

COLIN, F. 1984. Etude pétrologique des alterations de pyroxénite du gisement nickélifère de Niquelândia (Brésil).Tese de "Doctoral de spécialité".Université Paris VII. 137p. 
COLIN, F.; NOACK, Y.; TRESCASES, J. J.; NAHON, D. 1985. L'alteration latéritique debutant dês piroxénites de Jacuba, Niquelândia, Brésil. Clay Minerals, 20:93-113

COLIN, E; NAHON, D.; TRESCASES, J. J. \& MELFI, A.J. 1990 Lateritic weathering of pyroxenites at Niquelândia, Goiás, Brazil: The super-gene behaviour of nickel. Econ. Geol., 85:1010-1023.

CORREA, S. L. A.; OLIVEIRA, N. P. \& SCHWAB, R. G. 1984. Alguns aspectos mineralógicos e geoquímicos da laterita niquelífera do Vermelho, serra dos Carajás, e suas implicações genéticas. In: CONG. BRAS. GEOL., 33, Rio de Janeiro, Anais... Rio de Janeiro, SBG. v. 10, p. 4838-4849.

ESSON, J. \& SANTOS, L.C.S. dos 1978. The ocurrence, mineralogy and chemistry of some garnierites from Brazil. Bull, du Bureau de Recherches Géologiques et Minières.. Section II, 3:263-274.

GERTH, J.-1990 - Unit-cell dimensions of pure and trace metal-associated goethites. Geochimica et Cosmochimica. Acta, 54:363-371.

NICKEL, E. H. \& THORNBER, M. R. 1977. Chemical constraints on the weathering of serpentinites containing nickel-iron sulphides. Journ. ofGeoch. Explor. 8:235-245.

OLIVEIRA, S.M.B. de 1980. Alteração intempérica das rochas ultrabásicas de Santa Fé (GO) e gênese do depósito niquelífero. São Paulo, 220 p. (Tese de doutoramento. Instituto de Geociências/USP).

OLIVEIRA, S.M.B. de \& TRESCASES, J.J. 1980. Geoquímica da alteração supérgena das rochas ultramáficas de Santa Fé (Goiás-Brasil). Rev. Bras. Geoc., 10(4):243-257.
OLIVEIRA, S.M.B. de \& TRESCASES, J.J. 1982. Estudo mineralógico e geoquímico da laterita niquelífera de Niquelândia-Goiás. In: CONGRESSO BRASILEIRO DE GEOLOGIA, 32, Salvador, 1982. Anais. Salvador, SBG. v. 3, p.1 183 - 1190

OLIVEIRA, S.M.B. de; TRESCASES, J. J.; MELFI, A.J. 1992. Lateritic nickel deposits of Brazil. Mineralium Deposita, 27:137-146.

TRESCASES, J. J.; DINO, R. \& OLIVEIRA, S. M. B. de 1986. Un gisement de nickel supergène en zone semi-aride: São João do Piauí (Brésil). In: RODRIGUEZ- CLEMENTE, R \& TARDY, Y (eds.) Geochemistry and mineral formation in the earth surface: Proceedings of the International Meeting Geochemistry of the earth surface and Processes of Mineral Formation. Madrid, Consejo Superior de Investigaciones Científicas, p. 273-288.

WEAVER, C. E. \& POLARD, L. D. 1973. The chemistry of clay minerals. Amsterdam, Elsevier. 213 p. (Developments in Sedimentology, 15).

ZEISSINK, H. E. 1969. The mineralogy and geochemistry of a nickeliferous laterite profile (Greenvale, Queensland, Australia). Mineralium Deposita, 4:132-152.

MANUSCRITO A833

Recebido em 24 de fevereiro de 1995 Revisão do autor em 15 de outubro de 1995 Revisão aceita em 18 de dezembro de 1995 